\title{
Notas sobre os Reflexos Intergeracionais da Expansão dos Direitos Fundamentais
}

\author{
Guilherme Ricken ${ }^{*}$
}

\begin{abstract}
Resumo: O presente artigo tem por escopo delinear algumas consequências intergeracionais oriundas da expansão dos direitos fundamentais. Para tanto, será exposto, em um primeiro momento, o itinerário histórico da afirmação dos direitos fundamentais no mundo ocidental, enfatizando-se que eles surgiram como direitos de liberdade. Em seguida serão mostrados os reflexos da contínua ampliação desses direitos, como a intervenção do Estado na economia e o endividamento público, e seus corolários, quais sejam, ciclos econômicos, inflação e crises. Por fim, será apresentada uma teoria liberal para os direitos fundamentais adequada ao princípio da equidade intergeracional, baseada na ética da liberdade de Murray Rothbard.
\end{abstract}

Palavras-Chave: Escola Austríaca, direitos fundamentais, finanças públicas, liberalismo.

\section{Notes On the Intergenerational Reflections of the Expansion of Fundamental Rights}

\begin{abstract}
The aim of this article is to outline some intergenerational consequences arising from the expansion of fundamental rights. To do so, it will be exposed, at first, their historic route in the Western world, emphasizing that they emerged as rights of freedom. In the next moment, we will show the effects of the continued expansion of those rights, like the state intervention in the economy and the public debt, and its corollaries, namely, economic cycles, inflation and crises. Finally, we intend to present a liberal theory of the fundamental rights that is adequate to the principle of intergenerational equity, based on Murray Rothbard's ethic of liberty.
\end{abstract}

Keywords: Austrian School of Economics, fundamental rights, public finance, liberalism.

Classificação JEL: B53, Y80

\footnotetext{
" Guilherme Ricken é mestrando em Direito Econômico na Universidade de São Paulo (USP) e consultor jurídico da Câmara Municipal de Taubaté. Cursou a graduação em Direito na Universidade Federal de Santa Catarina (UFSC), foi bolsista do Programa Institucional de Bolsas de Iniciação Científica (PIBIC/CNPq) e participou de diversos cursos de extensão acadêmica.

E-mail: herr_ricken@msn.com
} 


\section{I - INTRODUÇÃo}

A preocupação com o legado a ser recebido pelas gerações futuras é um traço corrente na sociedade. Pais e mães esforçam-se para que seus filhos vivam em condições melhores do que aquelas que eles tiveram. Os ambientalistas, receosos da paulatina degradação do planeta, alertam para as dificuldades a serem enfrentadas pelas pessoas no futuro em matéria de qualidade de vida. Os membros da classe política, desejosos de verem seus nomes cravados nos anais da história, não raro estimulam a construção de obras monumentais, que devem sobreviver para a posteridade. Há atitudes tomadas no presente, portanto, que guardam maior interesse com os resultados futuros do que com os imediatos.

Em que pese a ideia de intergeracionalidade permear uma série de relações sociais, sua influência na seara do direito ainda é incipiente. Ainda que determinados ramos da ciência jurídica tratem brevemente do assunto, como o direito ambiental e o previdenciário, sua importância no âmbito normativo ainda não foi devidamente mensurada. Isso não significa, entretanto, que a maior parte das medidas adotadas pelo legislador não possua repercussões intergeracionais. Elas tanto refletem nas gerações vindouras como o fazem no presente. E é justamente aos direitos fundamentais que corresponde relevante parcela das consequências jurídicas entre as gerações.

Dessa forma, o presente artigo propõe-se a delinear alguns reflexos intergeracionais da expansão dos direitos fundamentais. O rol desses direitos existente hoje é consideravelmente mais extenso do que aquele que havia nos séculos passados. A consequência imediata decorrente de tal fato é que os cidadãos dos países ocidentais podem gozar de um amplo número de faculdades garantidas pelo Estado. Há resultados, contudo, não tão visíveis, cuja principal manifestação é o aumento da interferência estatal na vida dos indivíduos e da comunidade. Esse incremento é acompanhado da debilitação financeira das contas públicas, que cada vez mais devem fazer frente a um crescente número de compromissos, notadamente de políticas públicas que promovam a efetivação dos direitos fundamentais. A dívida pública, a inflação e os ciclos econômicos são alguns dos problemas com os quais as gerações futuras terão de lidar em razão da deterioração das finanças governamentais.

Cabe, ainda a título introdutório, realizar um esclarecimento semântico acerca do conceito de direitos fundamentais apresentado neste artigo. A utilização da expressão "direitos fundamentais" em detrimento da expressão "direitos humanos" foi preferida por guardar maior relação com o ordenamento jurídico positivo. Os direitos fundamentais são sempre direitos humanos, mas a recíproca nem sempre é verdadeira. Enquanto aqueles encontram-se inseridos na legislação, estes são pretensões supraestatais, reivindicações emancipatórias que só se tornam direitos fundamentais ao serem positivados. Assim, a expansão legislativa que ocasiona reflexos intergeracionais somente pode estar vinculada a direitos fundamentais, não a direitos humanos, pois estes ainda não fazem parte da ordem normativa.

\section{II - Os Direitos Fundamentais na Tradição Jurídica Ocidental, ou os} Direitos Fundamentais Nascem como Direitos De Liberdade

A Idade Moderna, cujo início simbólico e convencionado se deu com a invasão e tomada de Constantinopla pelos turcos otomanos no ano de 1453, foi um período que presenciou amplas mudanças econômicas, políticas e sociais em relação à época imediatamente anterior, a Idade Média. A chegada dos europeus à América, a reforma protestante, a ampliação da economia monetarizada e mercantil e a consolidação dos Estados nacionais, além de outros acontecimentos, acarretaram profundas alterações na vida material e 
intelectual no velho continente. Tais mudanças tiveram reflexos entre os pensadores do período, sendo os direitos fundamentais um produto da filosofia moderna, nascida no século XVII'.

A cultura da Europa moderna não foi amplamente segregada da esfera espiritual. Apesar do interesse pela leitura dos autores clássicos gregos e romanos, reforçado pela ascensão do humanismo, os filósofos modernos ainda conformavam seus pensamentos de acordo com dogmas cristãos. Nem mesmo Gottfried Leibniz (1646-1716), Baruch Spinoza (1632-1677) e Samuel von Pufendorf (16321694), expoentes do mos geometricus de conhecimento da ética e do direito natural, ou Hugo Grócio (1583-1645), tido como o primeiro a elaborar uma teoria secularizada do direito, esconderam as influências religiosas em suas obras $^{2}$. Os direitos fundamentais, portanto, tiveram como fonte primária a teologia cristã, ainda que esta não apresentasse um corpo único e coerente, dadas as divisões religiosas na Europa do período ${ }^{3}$.

Foi no século XVIII, notadamente com as revoluções americana, em 1776, e francesa, em 1789, que os direitos fundamentais passaram a ganhar destaque. Eles foram invocados - embora em uma dimensão pré-jurídica, ainda como direitos humanos - enquanto forma de justificação das posições tomadas contra a metrópole inglesa, na América, e contra as instituições do Ancien Régime, na França. A Declaração de Direitos de Virgínia e a Declaração de Independência dos Estados Unidos da América, bem como a Declaração dos Direitos do Homem e do Cidadão, positivaram direitos humanos tidos por seus subscritores como naturais e inalienáveis, alterando as bases da legitimidade política e marcando a as-

${ }^{1}$ LOPES, José Reinaldo de Lima. O Direito na História: Lições Introdutórias. 3a ed. São Paulo: Atlas, 2011. p. 159-160; VILLEY, Michel. Le droit et les droits de l'homme. 3a ed. Paris: PUF, 1998. p. 131.

${ }^{2}$ KROESCHELL, Karl. Deutsche Rechtsgeschichte: seit 1650. 4a ed. Köln: Böhlau, 2005. p. 65.

${ }^{3}$ VILLEY. Le droit et les droits de l'homme. p. 131. censão de uma nova relação entre governantes e governados ${ }^{4}$.

Inseridos tanto na Constituição dos Estados Unidos de 1787 - após a adoção da Bill of Rights, em 1789, cuja ratificação ocorreu dois anos depois - quanto na Constituição da França de 1791, cada uma com suas especificidades, os direitos humanos, evocados como pretensões supraestatais contra as arbitrariedades perpetradas contra os súditos americanos e franceses, tornaram-se direitos fundamentais, reivindicações emancipatórias que a partir de então passaram a fazer parte dos respectivos ordenamentos jurídicos. Eles se tornaram a primeira geração - ou dimensão ${ }^{5}$ - dos direitos fundamentais, marcada por características individualistas - próprias da filosofia da época, em que a sociedade era vista como a soma de indivíduos isolados, que se organizavam pelo contrato social - e que, por isso, privilegiou os direitos de liberdade ${ }^{6}$.

A primeira geração dos direitos fundamentais, portanto, fundou-se nas lutas contra os privilégios nobiliárquicos e clericais, enraizados nas sociedades de então. Os direitos civis e políticos conquistados eram sobretudo direitos de liberdade, que teriam por sujeito o homem livre, tanto da estrutura estamental quanto do arbítrio do monarca. No Estado liberal, baseado em um modelo econômico

${ }^{4}$ COMPARATO, Fábio Konder. A Afirmação Histórica dos Direitos Humanos. 3a ed. São Paulo: Saraiva, 2003. p. 49; MORAES, Alexandre de. Direitos Humanos Fundamentais: Teoria Geral. Comentários aos arts. $1^{\circ}$ a $5^{\circ}$ da Constituição da República Federativa do Brasil. Doutrina e Jurisprudência. 9a ed. São Paulo: Atlas, 2011. p. 9.

${ }^{5} \mathrm{O}$ termo "dimensão" é preferido por alguns autores porque, ao contrário do termo "geração", ele seria mais explícito em relação ao fato de que os direitos fundamentais posteriores não suprimem os anteriores, apenas somam-se a eles. Entretanto, utilizar-se-á aqui o termo "geração", pois ele não parece denotar nada além de que alguns direitos fundamentais surgiram após outros, sem fazer supor que os mais antigos foram substituídos pelos mais recentes.

${ }^{6}$ BONAVIDES, Paulo. Curso de Direito Constitucional. 22a ed. São Paulo: Malheiros, 2008. p. 562-563; LOPES. O Direito na História: Lições Introdutórias. p. 162. 
cuja retórica afastava a atuação do Estado, o cidadão seria o principal ator no processo de construção da nova sociedade. É a fase inicial do constitucionalismo ocidental, em que o poder do Estado passa a sofrer maiores e mais claras limitações a partir de documentos solenes e os cidadãos começam a desfrutar de direitos oponíveis ao poder soberano ${ }^{7}$.

Já a segunda geração dos direitos fundamentais foi gestada especialmente na metade final do século XIX e amealhou um lugar definitivo na esfera jurídica durante o século posterior. São direitos sociais, culturais e econômicos, que tinham como principal valor a igualdade material, em oposição à chamada igualdade formal, característica da geração anterior. Ganharam corpo nesse momento histórico os direitos prestacionais, a exemplo dos direitos trabalhistas, previdenciários, à educação, à saúde e ao saneamento básico. São direitos anticapitalistas, que demandam atitudes positivas do Estado em maior escala, diferentemente dos direitos fundamentais de liberdade, cujo exercício seria garantido na medida em que o poder público não interferisse nas esferas individuais dos cidadãos ${ }^{8}$.

Os direitos fundamentais de segunda geração se realizam com plenitude no âmbito do Estado de bem-estar social - ou welfare state. Tal modelo de Estado exerce um papel interventivo e promocional, envolvendo-se no processo econômico e normatizando amplamente a vida dos indivíduos. Em que pese o fato de políticas interventivas terem sido usuais no Ocidente no início do século XX, notadamente após a crise econômica de 1929, é com o fim da Segunda Guerra Mun-

7 PORTANOVA, Rogério. Direitos Humanos em Perspectiva. Seqüência, Florianópolis, n. 53 (dez. 2006): 129-144. p. 131-132; BONAVIDES. Curso de Direito Constitucional. p. 563.

${ }^{8}$ COMPARATO. A Afirmação Histórica dos Direitos Humanos. p. 53; PORTANOVA. Direitos Humanos em Perspectiva. BONAVIDES. Curso de Direito Constitucional. p. 564. dial que o Estado de bem-estar apresenta-se em toda a sua concretude. Ele foi construído gradativamente, podendo suas origens serem traçadas até o new deal norte-americano, a ascensão do keynesianismo e as políticas sociais inglesas do segundo pós-guerra9 ${ }^{9}$

A terceira geração dos direitos fundamentais é composta pelos direitos que exprimem como valor maior a solidariedade. Os destinatários desses direitos não são mais o indivíduo isolado ou um grupo de indivíduos, mas o próprio gênero humano. São direitos difusos, de nítido caráter universalista. Fala-se agora em direito ao desenvolvimento, à paz, ao meio ambiente sadio e equilibrado, à propriedade sobre o patrimônio material e imaterial comum da humanidade e à comunicação entre os povos. No âmbito da sociedade civil presencia-se uma ampliação da atuação das organizações não-governamentais, com alterações na representação política e nas demandas democráticas. Os direitos de segunda geração não são esquecidos, uma vez que a demanda por prestações estatais não diminuiu $^{10}$.

A globalização política e econômica do final do século XX foi a principal causa do surgimento da quarta geração dos direitos fundamentais, que marca a fase de consolidação e institucionalização do Estado de bem-estar social. Fazem parte da nova normatividade os direitos à democracia, à informação e ao pluralismo, em consonância com a máxima universalidade da sociedade. O espaço da democracia não está mais circunscrito ao território do Estado nacional, mas inclui o espaço internacional e, também, as experiências locais, a exemplo da democracia participativa. A própria democracia deve ser incentivada nas instâncias

9 STRECK, Lenio Luiz ; MORAIS, José Luiz Bolzan de. Ciência Política e Teoria do Estado. 5a ed. Porto Alegre: Livraria do Advogado, 2006. p. 78.

10 BONAVIDES. Curso de Direito Constitucional. p. 569; PORTANOVA. Direitos Humanos em Perspectiva. p. 136-137. 
tradicionais, aperfeiçoada pelos aprimoramentos tecnológicos e pela maior difusão de informações à população ${ }^{11}$.

Fala-se hoje, ainda, em uma quinta geração de direitos fundamentais, com conteúdo voltado eminentemente ao direito à paz - com maior densidade normativa do que quando fora incluído no rol de direitos fundamentais de terceira geração. $\mathrm{O}$ direito à paz seria um direito diretamente vinculado ao direito à vida, mostrando-se fundamental ao progresso contínuo das nações. Ele é tratado como pressuposto para uma convivência humana de qualidade e, portanto, foi positivado em diversos documentos nacionais e internacionais, tanto no âmbito da Organização das Nações Unidas quanto a nível regional. É mais um direito que, inserido no âmbito do Estado de bem-estar social, demanda prestações positivas do poder público e, assim, ingerência na vida privada dos cidadãos ${ }^{12}$.

O desenvolvimento histórico dos direitos humanos, portanto, sendo positivados e transformados em direitos fundamentais, evidencia um itinerário que se inicia com menores atuações do Estado na vida social e econômica e culmina com a elevada expansão legislativa do Estado de bem-estar social. Os direitos fundamentais de primeira geração se baseavam precipuamente na liberdade, fazendo com que suas garantias se realizassem mediante um não-fazer, i.e., através da abstenção do poder público em interferir na liberdade, na vida e na propriedade dos cidadãos. As gerações seguintes de direitos fundamentais, ao contrário, demandam um Estado atuante, garantindo direitos prestacionais. $\mathrm{O}$ Estado, por meio da tributação, distribuirá o patrimônio alheio a pretexto de exercer a justiça social ${ }^{13}$.

11 STRECK ; MORAIS. Ciência Política e Teoria do Estado. p. 131; BONAVIDES. Curso de Direito Constitucional. p. 571.

12 BONAVIDES. Curso de Direito Constitucional. p. 579-583.

${ }^{13}$ Para uma crítica da dicotomia entre direitos positivos (prestacionais) e negativos (de abstenção do Estado), ver HOLMES, Stephen \& SUNSTEIN, Cass. The Cost
Essa transformação nas funções do Estado foi calcada igualmente em mudanças na teoria jurídica, as quais foram guiadas por uma falsa ciência econômica. A ascensão dos direitos prestacionais à categoria de direitos fundamentais foi baseada nos argumento equivocado de que o livre comércio progredia em detrimento dos trabalhadores e de que o capitalismo nascido da revolução industrial teria reduzido os padrões de vida material da classe operária. Ao contrário, a qualidade de vida e os ganhos de produtividade aumentaram substancialmente com o crescimento do livre mercado. Todavia, o entusiasmo pelo planejamento, dominante na teoria jurídica e nas práticas políticas e econômicas desde o surgimento do Estado social e consolidado no welfare state, acarretou consequências indesejadas e materializadas em crises econômicas de difícil solução ${ }^{14}$.

\section{III - Consequências Intergeracionais DA EXPANSÃo dos DiREITOS Fundamentais}

O itinerário histórico dos direitos fundamentais mostra uma constante expansão que, para além de atingir tão somente a quantidade de direitos, atuou especialmente sobre seus respectivos conteúdos. Os direitos fundamentais de primeira geração constituíam-se sobretudo de garantias contra o Estado, tendo por base os valores da liberdade e da igualdade jurídica. São direitos cuja efetivação exigiam do poder público, no máximo, a constituição e a manutenção de um aparato judiciário e policial que coíba agressões individuais injustas. As gerações posteriores de

of Rights: Why Liberty Depends on Taxes. New York: W.W. Norton, 2000.

14 HAYEK, Friedrich August. Law, Legislation and Liberty: A New Statement of the Liberal Principles of Justice and Political Economy. London: Routledge, 2012. p. 65-66; MISES, Ludwig von. A Mentalidade Anticapitalista. 2a ed. São Paulo: Instituto Ludwig von Mises Brasil, 2010. p. 34. 
direitos fundamentais, ao contrário, ao buscarem suas justificativas primordialmente na igualdade material e na solidariedade - forçada - entre as pessoas, limitaram sobremaneira os direitos fundamentais de primeira geração e trouxeram direitos eminentemente prestacionais, que exigem uma ativa participação do Estado na vida social e econômica ${ }^{15}$.

Os direitos sociais não são apenas poderes de agir, tal qual eram os direitos fundamentais de primeira geração, mas poderes de exigir. São, portanto, direitos de crédito, a serem prestados pelo Estado, seu sujeito passivo. A responsabilidade estatal pelo atendimento aos direitos sociais, no ordenamento jurídico brasileiro, mostra-se induvidosa, constando expressamente em diversos dispositivos constitucionais ${ }^{16}$. A efetivação dos direitos prestacionais, entretanto, demanda gastos muitos maiores por parte do Estado, pois este torna-se o fornecedor de uma ampla gama de bens, serviços e mesmo de benefícios pecuniários para os cidadãos. Dessa forma, o Estado precisará adquirir os meios de financiamento do novo rol de direitos, o que fará pelo método político, i.e., pelo confisco via coerção - arrecadação tributária -, e não pelo método econômico, predominante no livre mercado, que consiste na produção e em trocas voluntárias ${ }^{17}$.

Em que pese a imoralidade da aquisição de riqueza mediante confisco, tal como age o Estado, essa prática está naturalizada - assim como as instituições que a promovem, a exemplo do banco central, que o faz via inflação monetária - ao ponto dos tratadistas de finanças públicas e economia política pouco

\footnotetext{
15 BOBBIO, Norberto. A Era dos Direitos. Rio de Janeiro: Elsevier, 1992. p. 18; MARTINS NETO, João dos Passos. Direitos Fundamentais: Conceito, Função e Tipos. São Paulo: Revista dos Tribunais, 2003. p. 166.

16 FERREIRA FILHO, Manoel Gonçalves. Direitos Humanos Fundamentais. 2a ed. São Paulo: Saraiva, 2010. p. 67-68.

17 ROTHBARD, Murray. Man, Economy and State with Power and Market. 2a ed. Auburn: Ludwig von Mises Institute, 2009. p. 1254.
}

discutirem os gastos governamentais, limitando-se meramente a descrevê-los. Argumenta-se que as complexidades da economia contemporânea tornariam o gasto público algo imperativo, o que não tem bases racionais ${ }^{18}$. Os gastos governamentais, sejam eles realizados mediante transferências - puros subsídios a indivíduos - ou pela utilização direta de recursos - uso conforme a vontade do Estado -, são apropriações involuntárias de riqueza do livre mercado para o Estado ${ }^{19}$.

As transferências permitem a alocação de recursos conforme a habilidade de determinada pessoa ou grupo político dominar o aparato estatal. Elas deslocam a riqueza dos usos eficientes para os ineficientes, prolongando a vida de firmas inábeis, distorcendo o sistema produtivo e deformando a mobilidade dos fatores de produção. Ocorre uma redução generalizada da qualidade de vida, pois o desvio de energia da produção para a política e o desestímulo dos produtores em prol dos agentes econômicos inaptos gera a insatisfação dos consumidores. Enquanto no livre mercado as trocas fazem surgir benefícios mútuos, a interferência estatal faz com que alguém se beneficie em detrimento de outrem. A produção de bens e serviços passa, assim, a despertar menor interesse do que a briga política e a disputa pelo aparelhamento do Estado $^{20}$.

Já a utilização direta de recursos redireciona fatores de produção para os fins escolhidos pelo governo. Este fornece bens e serviços supostamente gratuitos à população, sob pretexto de realizar investimentos - seja em infraestrutura, educação, saúde ou quaisquer outras áreas. Todavia, nem os bens e serviços são gratuitos, pois são pagos pelos contribuintes, nem os gastos são investimentos, constituindo-se de fato em consumo. A aloca-

${ }^{18}$ PAUL, Ron. O Fim do FED: Por Que Acabar com o Banco Central. São Paulo: É Realizações, 2011. p. 11; ROTHBARD. Man, Economy and State with Power and Market. p. 1253.

\footnotetext{
${ }^{19}$ Idem. Ibidem, p. 1254.

${ }^{20}$ Idem. Ibidem, p. 1255-1256.
} 
ção errônea de recursos beneficia determinados usuários às custas dos não usuários, com total desatenção para o fato de que os bens "gratuitos" serão sempre insuficientes, visto que a demanda será invariavelmente crescente. Além disso, como o Estado não tem maneira de chegar a decisões racionais sobre como investir as verbas disponíveis, nem possui qualquer estímulo à eficiência, ele pagará por bens e serviços acima do preço de mercado, gerando uma busca por empregos burocráticos improdutivos ${ }^{21}$.

Tanto as transferências como a utilização direta de recursos pelo Estado, utilizadas, entre outros fins, para a promoção de políticas públicas com vistas à efetivação dos direitos fundamentais de cunho social, distorcem o conhecimento dos agentes econômicos e, consequentemente, suas atitudes no mercado $^{22}$. Tal interferência na economia é acompanhada de endividamento público, pois o Estado se propõe a realizar mais do que aquilo que está financeiramente apto a suportar. Dado que há um limite para a quantidade de dinheiro que o fisco pode obter dos cidadãos sem criar inconvenientes para a manutenção da própria estrutura de poder e dominação estatal, a prática corrente na esfera pública consiste em recorrer ao endividamento, interno e externo, como tentativa de sustentar os crescentes gastos públicos.

O endividamento público não é uma novidade do século $X X$, mas foi nesse período que ele foi estendido e deixou de ser visto negativamente pela maior parte dos acadêmicos. A principal influência na teoria econômica para que isso ocorresse foi o keynesianismo, que suplantou os preceitos clás-

\footnotetext{
${ }^{21}$ HAYEK, Friedrich August. The use of knowledge in society. The American Economic Review, Nashville, v. 35, n. 4 (Sep. 1945): 519-530. p. 519; MISES, Ludwig von. O Cálculo Econômico sob o Socialismo. São Paulo: Instituto Ludwig von Mises Brasil, 2012. p. 45; ROTHBARD. Man, Economy and State with Power and Market. p. 1259-1267.

${ }^{22}$ Idem. Ibidem, p. 1268.
}

sicos de prudência fiscal. John Maynard Keynes (1883-1946), ao lidar com os problemas do desemprego e da crise econômica, privilegiou a lógica da política econômica em detrimento das regras de longo prazo. Para ele, o Estado deveria desempenhar o papel de indutor da economia em tempos de retração da demanda privada, como forma de superar a estagnação. Entretanto, ao fazer isso, o Estado ignora a parcimônia fiscal e a monetária, que são proteções contra as tendências perdulárias do ser humano, camufladas em políticas de pleno emprego e de atendimento às demandas sociais pela efetivação de direitos prestacionais e pela implementação de novos direitos ${ }^{23}$.

Substituir a prudência financeira pelo endividamento acarreta, além de danos presentes, também prejuízos para as próximas gerações. A equidade intergeracional "significa que os empréstimos públicos e as despesas governamentais não devem sobrecarregar as gerações futuras, cabendo à própria geração que delas se beneficia arcar com o ônus respectivo" 24 . Em que pese ser um princípio que tenha perdido parte de sua importância - possivelmente uma reflexão na esfera jurídica das políticas econômicas intervencionistas e promotoras de déficits públicos -, a equidade entre gerações deve ser levada em consideração quando da tomada de decisões em relação aos gastos públicos. Experiências passadas - e atuais, como mostra a crise na zona do euro ${ }^{25}$ - mostram como o endividamento pretérito,

${ }^{23}$ IORIO, Ubiratan J. Economia e Liberdade: a Escola Austríaca e a Economia Brasileira. 2a ed. Rio de Janeiro: Forense Universitária, 1997. p. 182.

24 TORRES, Ricardo Lobo. Tratado de Direito Constitucional Financeiro e Tributário, Volume V: O Orçamento na Constituição. 3a ed. Rio de Janeiro: Renovar, 2008. p. 308.

25 Para uma análise da maneira pela qual o endividamento público contribuiu para a crise econômica europeia, demonstrando como o aumento dos gastos públicos do passado está afetando a geração presente e continuará a influir sobre os rumos das gerações futuras, ver BAGUS, Phillip. The Tragedy of the Euro. Auburn: Ludwig von Mises Institute, 2010. 
ao destruir o estoque de capital, reduz a renda futura ${ }^{26}$.

A afronta ao princípio da equidade intergeracional também ocorre quando a dívida pública é monetizada, pois a introdução na economia de dinheiro sem lastro altera artificialmente as taxas de juros e distorce o cálculo econômico, gerando informações errôneas aos agentes e, consequentemente, maus investimentos. Os primeiros usuários do dinheiro novo - o próprio Estado, bancos e grandes empresas - serão os beneficiários da política intervencionista, mas são as classes média e baixa, sobretudo futuras, que arcarão com as crises econômicas e com a depreciação do valor da moeda. O pagamento da dívida, que invariavelmente precisará ser feito, é deixado para as gerações vindouras. $\mathrm{O}$ momento da liquidação será de instabilidade política e econômica, com consequências sociais negativas, especialmente para as camadas mais vulneráveis da população ${ }^{27}$.

A estabilidade econômica é requisito para que os cidadãos possam gozar dos direitos fundamentais, sobretudo do direito de propriedade. Contudo, a expansão monetária que surge como forma de o Estado financiar suas dívidas, geradas como forma de suprir o número cada vez maior de direitos fundamentais prestacionais, acarreta os ciclos responsáveis pelas turbulências econômicas. Um sistema monetário em que o Estado manipula o estoque de dinheiro na economia, podendo reduzir artificialmente as taxas de juros, dá origem aos ciclos de expansão e contração. A tomada de riscos nos períodos de expansão torna-se precipitada, pois o crédito ofertado não se encontra lastreado em poupança. Quando chega o período de contração, a geração seguinte passa a sofrer em função dos erros da geração passada, que foi influenciada pela intervenção estatal no mercado ${ }^{28}$.

${ }^{26}$ IORIO. Economia e Liberdade: a Escola Austríaca e a Economia Brasileira. p. 183.

${ }^{27}$ PAUL. O Fim do FED: Por Que Acabar com o Banco Central. p. 207-209.

${ }^{28}$ WOODS JR., Thomas E. Meltdown: A Free-Market Look at Why the Stock Market Collapsed, the Economy
Ampliar cada vez mais o rol dos direitos fundamentais sociais, como tem sido a tônica do moderno Estado ocidental, faz, assim, com que ele precise criar meios para pagar as dívidas geradas por sua atuação. Os métodos empregados para isso, a exemplo do monopólio de emissão da moeda, trazem reflexos perniciosos para as gerações futuras. O fim de tal monopólio, representado pelo banco central, interromperia a acumulação de débitos pelo Estado e, consequentemente, impeliria ao fim do modelo assistencialista estatal tal qual o conhecemos. $\mathrm{O}$ poder público seria forçado a atuar de maneira austera, prestando somente os serviços essenciais às garantias dos direitos de liberdade $\mathrm{e}$ propriedade, como os judiciais e os de segurança pública. Além disso, o fim do estímulo artificial à economia terminaria o ciclo econômico, impedindo que as políticas intervencionistas presentes afetem negativamente o patrimônio das gerações futuras, especialmente pela depreciação do valor da moeda ${ }^{29}$.

A expansão do crédito e o aumento da quantidade de dinheiro em circulação, ao contrário do que creem os formuladores de políticas da maioria dos governos, não são eficazes para manter as taxas de juros sustentavelmente abaixo do que estariam no livre mercado $^{30}$. Os juros são o preço do dinheiro, refletindo o estoque de capital da economia. Ele é obtido apenas mediante poupança, uma privação presente com vistas a um benefício futuro. Um Estado assistencialista, que concede bens e presta um amplo número de serviços subsidiados à população, consome o estoque de capital da sociedade e a deixa sem provisões para o futuro. $\mathrm{O}$ paternalismo garantidor de direitos sociais faz com que os benefícios da intensificação da cooperação so-

Tanked, and Government Bailouts Will Make Things Worse. Washington: Regnery Publishings, 2009. p. 109110.

${ }^{29}$ PAUL. O Fim do FED: Por Que Acabar com o Banco Central. p. 17-18.

${ }^{30}$ MISES, Ludwig von. Ação Humana: Um Tratado de Economia. 3a ed. São Paulo: Instituto Ludwig von Mises Brasil, 2010. p. 231. 
cial, a exemplo da divisão do trabalho e dos ganhos de produtividade, que deveriam ser repassados às próximas gerações, percam-se paulatinamente ${ }^{31}$.

Outra consequência intergeracional da expansão dos direitos fundamentais de prestação ocorre diretamente no âmbito familiar, especialmente no tratamento reservado aos idosos. Os direitos referentes à seguridade social fizeram com que as pessoas se tornassem menos zelosas quanto às preocupações relativas ao bem-estar futuro. Os idosos, que antes do welfare state sobreviviam do dinheiro poupado durante a vida e da ajuda dos filhos adultos, passaram a depender de pensões estatais. Isso fez com que a importância da poupança fosse negligenciada e a ligação entre pais e filhos fosse prejudicada. Além disso, os trabalhadores jovens, que usualmente possuem menos riqueza acumulada, tornaram-se os subsidiadores dos mais velhos, que tendem a dispor de maiores recursos poupados ${ }^{32}$.

\section{IV - Uma Proposta Liberal para os Direitos Fundamentais}

A contínua ampliação da quantidade de direitos fundamentais, notadamente de cunho prestacional, fez com que o Estado precisasse ofertar um número cada vez mais amplo de bens e serviços subsidiados à população. Como o preço desses bens para os seus beneficiários é próximo de zero, a tendência é que a demanda por eles aumente progressivamente. Dessa forma, o Estado precisa de recursos crescentes para financiar as benesses do assistencialismo. Ele os obtém sobretudo mediante a cobrança de tributos, mas o faz igualmente pela produção de dinheiro sem lastro. Todavia, contando com receitas insuficientes para fazer frente às despesas, o Estado

${ }^{31}$ Idem. Ibidem, p. 186.

32 WOODS JR., Thomas E. The Church and the Market: A Catholic Defense of the Free Economy. Lanham: Lexington Books, 2005. p. 149. recorre ao endividamento público, que deixou de ser visto de maneira negativa após a ascensão do keynesianismo como teoria econômica dominante. Na segunda metade do século $X X$, na seara governamental, acreditava-se na inesgotabilidade dos recursos públicos ${ }^{33}$.

Alterações nesse quadro só podem ser realizadas mediante uma efetiva redução do papel do Estado na vida econômica e social, o que implica a negativa de reconhecimento do caráter de fundamentalidade dos direitos prestacionais $^{34}$. Isso se justifica pelo fato de que as soluções oferecidas nas décadas de 1980 e 1990 não foram suficientes, mostrando-se meramente paliativas. As prescrições do Consenso de Washington ${ }^{35}$, adotadas na América Latina, tinham por retórica o controle dos défices governamentais. Entretanto, elas foram acompanhadas de aumentos dos gastos públicos. Associados a um aumento artificial das taxas de juros capitaneado pelo banco central dos Estados Unidos e a uma redução na atividade econômica, eles colaboraram para a ampliação do endividamento público brasileiro ${ }^{36}$.

Assim, segundo uma teoria política liberal - com tendências libertárias -, os direitos fundamentais, para mostrarem-se adequados à responsabilidade individual e ao princípio de que os empréstimos públicos e as despe-

${ }^{33}$ MENDES, Gilmar. Lei de Responsabilidade Fiscal, Correlação Entre Metas e Riscos Fiscais e o Impacto dos Déficits Públicos para Gerações Futuras. Revista Diálogo Jurídico, n. 14. Salvador (jun./ago. 2002). p. 02.

34 Atitude que seria especialmente difícil no caso brasileiro, pois grande parte dos direitos fundamentais sociais encontram-se positivados na Constituição Federal.

${ }^{35}$ WILLIAMSON, John. Latin American Adjustment: How Much Has Happened? Washington: Peterson Institute for International Economics, 1990. Ver sobretudo o capítulo 2, What Washington means by policy reform.

36 SAYAD, João. Aspectos Políticos do Déficit Público. In: POMERANZ, Lenina ; MIGLIOLI, Jorge \& LIMA, Gilberto Tadeu (Orgs.). Dinâmica Econômica do Capitalismo Contemporâneo: Homenagem a $\mathbf{M}$. Kalecki. São Paulo: Edusp, 2011. p. 244-246. 
sas governamentais feitos no presente não devem onerar as gerações futuras, precisam ficar restritos aos direitos à vida, à liberdade e à propriedade privada. Tanto o direito à vida quanto à liberdade giram em torno do direito à propriedade. $\mathrm{O}$ direito fundamental à vida implica o direito de o homem encontrar e transformar recursos, produzindo aquilo que sustenta e faz avançar a vida. O produto dessa transformação é a propriedade, pela qual o homem aperfeiçoa sua existência e obtém os meios de sobrevivência. $\mathrm{O}$ enfraquecimento desse direito põe em perigo todos os demais direitos fundamentais ${ }^{37}$.

O direito de propriedade se estende ao corpo do indivíduo: o homem tem a propriedade de seu próprio corpo. Partindo dessa premissa, Murray Rothbard (1926-1995) deduz o axioma da não-agressão, segundo o qual é imoral e ilegítimo iniciar uma agressão contra um não-agressor. Isso vale tanto para os indivíduos nas relações intersubjetivas quanto para o poder público em suas relações com os particulares. A liberdade - que pode ser vista como uma manifestação do direito de propriedade sobre si mesmo -, a vida e a propriedade são direitos fundamentais por serem os únicos a respeitarem o princípio da não-agressão. Para serem protegidos, basta que não haja uma interferência ilegítima por parte de outro indivíduo. Os demais direitos, todavia, exigem alguma forma de agressão deliberada - que usualmente toma a forma de tributação, uma violência contra o direito de propriedade - para que possam ser efetiva$\operatorname{dos}^{38}$.

${ }^{37}$ ROTHBARD, Murray. Human Rights Are Property Rights. In: The Foundation for Economic Education, INC. (Comp.). Essays on Liberty. New York: Irvingtonon-hudson, 1959. p. 315.

38 ROTHBARD. Man, Economy and State with Power and Market. p. 1337; MODUGNO, Roberta A. Introduction - Law and Nature in the Work of Murray N. Rothbard. In: MODUGNO, Roberta A. (Ed.). Murray N. Rothbard vs. The Philosophers: Unpublished Writings on Hayek, Mises, Strauss, and Polanyi. Auburn: Ludwig von Mises Institute, 2009. p. 13; ROTHBARD. Human Rights are Property Rights. p. 316.
A doutrina liberal de Rothbard nega o relativismo ético, defendendo uma filosofia política que encontre valores básicos universalmente válidos para a vida em sociedade. Assim, ele se distancia da defesa praxeológica e avalorativa do livre mercado proposta por Ludwig von Mises (1881-1973). O fato deste basear seu liberalismo no subjetivismo de valores e fins torna-o um relativista ético, o que se contrapõe à proposta rothbardiana de uma ética absoluta, uma ética da liberdade. Para Mises, ancorado na praxeologia, os valores não são verdadeiros ou falsos, apenas expressam preferências subjetivas. Entretanto, Rothbard afirma haver verdades autoevidentes que provém a base para uma ética objetiva, formando um guia que permite a compreensão de quais são os objetivos do homem, i.e., quais fins estão de acordo com a natureza humana ${ }^{39}$. E o direito de auto-propriedade está em consonância com o objetivo natural do homem, a promoção de sua própria sobrevivência ${ }^{40}$.

Os direitos fundamentais, dessa maneira, são indissociáveis do direito de propriedade, pois tanto não há direitos fundamentais "que não sejam também direitos de propriedade, como esses direitos perdem sua incondicionalidade e clareza e se tornam confusos e vulneráveis quando os direitos de propriedade não são usados como padrão" ${ }^{41}$. Exemplo disso é o que ocorre com o suposto direito fundamental à liberdade de expressão. Tal direito aparentemente faculta qualquer indivíduo a dizer o que quer que deseje. Contudo, onde esse direito pode ser exercido? Não em uma propriedade alheia onde se tenha adentrado ilegalmente. O cidadão só pode exercer o direito à livre manifestação em sua própria propriedade ou na propriedade de alguém que tenha consentido, gratuita ou onerosamente, no exercício do direito. Não

\footnotetext{
${ }^{39}$ MODUGNO. Introduction - Law and Nature in the Work of Murray N. Rothbard. p. 16.

${ }^{40}$ Idem. Ibidem, p. 20.

${ }^{41}$ ROTHBARD, Murray. A Ética da Liberdade. São Paulo: Instituto Ludwig von Mises Brasil, 2010. p. 177.
} 
existe, assim, um direito autônomo à liberdade de expressão, apenas o direito de propriedade de alguém, que pode fazer com ela o que desejar ${ }^{42}$.

A mesma confusão teórica ocorre em relação aos direitos sociais. A extensa enumeração de tais direitos - notadamente no ordenamento jurídico brasileiro - aliada à sua diversificação, faz com que se perca a sua conexão com o direito de propriedade. A prestação de serviços educacionais, assistenciais e de saúde, bem como os investimentos públicos em obras infraestruturais que garantam os supostos direitos fundamentais ao transporte e à locomoção, entre outros, são caros e drenam recursos que seriam aplicados de maneira eficiente no livre mercado. Tais recursos não estão espalhados a esmo pelas ruas, prontos para serem recolhidos pelos agentes do Estado. Eles são propriedade dos cidadãos, que se veem obrigados a abrir mão dela contra suas vontades, mesmo sabendo que eles serão utilizados para subsidiar os membros menos eficientes da sociedade.

No livre mercado, políticas públicas só seriam executadas se um grupo de indivíduos pactuasse em tal direção. Não poderia haver um poder externo que os coagisse a entregar suas propriedades para que fossem utilizadas de maneira aleatória, como se alguém pudesse saber o que é melhor para os outros. A defesa da livre iniciativa e do livre mercado é essencial para uma transição intergeracional saudável e responsável, em que as gerações futuras não precisem arcar com as decisões erradas tomadas no presente. $\mathrm{O}$ progresso econômico e social não deriva da expansão dos gastos públicos necessária à efetivação da lista crescente de direitos fundamentais prestacionais, mas da criatividade e da inventividade dos indivíduos agindo livremente em sociedade. A redução da atuação estatal na economia permite que "seja aberta a possibilidade para homens desconhecidos - os empresários de amanhã - usarem sua habilidade e engenho,

\footnotetext{
${ }^{42}$ ROTHBARD. Man, Economy and State with Power
} and Market. p. 1338. proporcionando, desta forma, uma vida mais agradável para as gerações vindouras" 4 .

\section{V - Conclusões}

O compromisso com a efetivação dos direitos fundamentais faz com que o Estado planeje e execute um número cada vez maior de políticas públicas. Elas têm por meta, basicamente, fornecer bens e serviços subsidiados à população, o que acarreta uma demanda invariavelmente crescente. Para suprir a procura, o poder público precisa gastar cada vez mais dinheiro. Contudo, como ele não possui atividades produtivas, a maneira de obter recursos deve ser a tributação sobre a camada produtiva da população. Ainda que dessa forma se possa arrecadar uma grande soma, ela não é suficiente para fazer frente à miríade de despesas públicas. Só resta ao Estado, portanto, recorrer ao endividamento.

As consequências da dívida pública no campo econômico são visíveis, embora a classe política e boa parte da população se recusem a enxergá-las. A rolagem e as tentativas de pagamento da dívida fazem com que o Estado precise vender títulos públicos e colocar mais dinheiro na economia via banco central. Tanto uma quanto outra atitude distorcem o cálculo econômico e criam índices artificiais que enganam empreendedores e investidores, estimulando-os a tomarem atitudes que não adotariam caso os dados econômicos não estivessem alterados artificialmente. Taxas de juros baixas e crédito barato, como querem os governos, porém sem lastro em poupança, geram os ciclos econômicos.

Os ciclos de expansão e contração da economia refletem na esfera jurídica, mais especificamente na capacidade do Estado de continuar a realização de políticas públicas. Os períodos contracionistas são marcados por redução na atividade econômica, culminando em menor arrecadação tributária e, conse-

\footnotetext{
${ }^{43}$ MISES. Ação Humana: Um Tratado de Economia. p. 115.
} 
quentemente, na redução das verbas para a implementação de programas governamentais sociais. Isso significa, no âmbito do welfare state, que menos investimentos serão feitos em educação e infraestrutura, entre outros, que afetarão as futuras gerações. Estas também pagarão a conta da inflação, que traz sérios danos à estrutura produtiva e aos direitos de propriedade.

O Estado deve, portanto, agir de maneira austera. Contudo, como guardar dinheiro para o futuro? Como impedir que os políticos o gastem desordenadamente? Qual é o instrumento jurídico adequado para isso? O Legislador ainda não encontrou respostas para essas perguntas. Isso parece difícil no quadro constitucional brasileiro, que positiva uma ampla gama de direitos prestacionais, dificultando uma necessária abordagem liberalizante. Um futuro próspero para as gerações vindouras, contudo, passa por esses dilemas. cos 